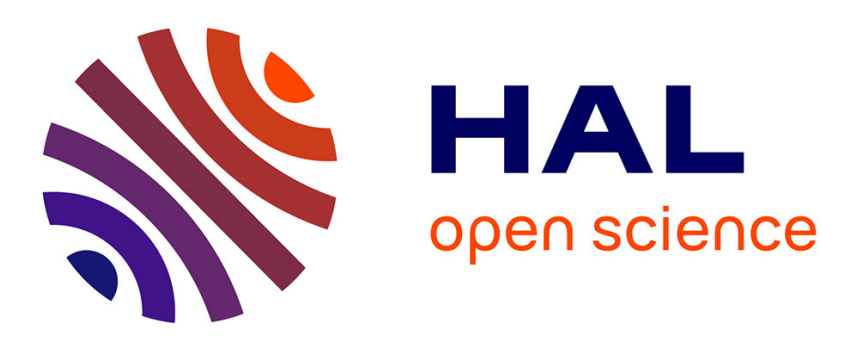

\title{
Influence of micromixing time and shear rate in fast contacting mixers on the precipitation of boehmite and NH 4 -dawsonite
}

Robin Lafficher, Mathieu Digne, Fabien Salvatori, Malika Boualleg, Didier Colson, François Puel

\section{To cite this version:}

Robin Lafficher, Mathieu Digne, Fabien Salvatori, Malika Boualleg, Didier Colson, et al.. Influence of micromixing time and shear rate in fast contacting mixers on the precipitation of boehmite and NH 4 -dawsonite. Chemical Engineering Science, 2018, 175, pp.343-353. 10.1016/j.ces.2017.10.011. hal-01654484

\section{HAL Id: hal-01654484 \\ https://hal-centralesupelec.archives-ouvertes.fr/hal-01654484}

Submitted on 14 Jun 2018

HAL is a multi-disciplinary open access archive for the deposit and dissemination of scientific research documents, whether they are published or not. The documents may come from teaching and research institutions in France or abroad, or from public or private research centers.
L'archive ouverte pluridisciplinaire HAL, est destinée au dépôt et à la diffusion de documents scientifiques de niveau recherche, publiés ou non, émanant des établissements d'enseignement et de recherche français ou étrangers, des laboratoires publics ou privés. 
To cite this article: R. Lafficher, M. Digne, F. Salvatori, M. Boualleg, D. Colson, F. Puel (2018) Influence of micromixing time and shear rate in fast contacting mixers on the precipitation of boehmite and NH4-

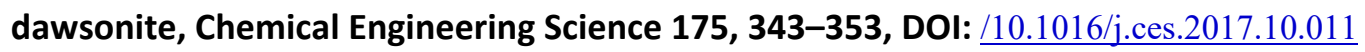

\title{
Influence of micromixing time in fast contacting mixers on the precipitation of boehmite and NH4-dawsonite
}

\author{
$\underline{\text { Robin Lafficher }}^{\mathrm{a}, \mathrm{b}}$, Mathieu Digne ${ }^{\mathrm{a}}$, Fabien Salvatori ${ }^{\mathrm{a}}$, Malika Boualleg ${ }^{\mathrm{a}}$, Didier Colson $^{\mathrm{b}}$ and François Puel ${ }^{\mathrm{c}}{ }^{*}$ \\ a IFP Energies Nouvelles ; BP 3, F-69360 Solaize, France \\ ${ }^{\mathrm{b}}$ Univ Lyon, Universite Lyon 1, CNRS, UMR5007, LAGEP, F-69622 LYON, France \\ ${ }^{\mathrm{c}}$ LGPM, Laboratoire de Génie des Procédés et Matériaux, CentraleSupélec, Université Paris-Saclay, 3 rue Joliot \\ Curie, 91192 Gif-sur-Yvette, France
}

${ }^{*}$ Corresponding author Tel: $+33(0) 6.65 .58 .58 .64$

Email: francois.puel@,centralesupelec.fr (François Puel)

\begin{abstract}
The textural properties of $\gamma$-alumina catalyst supports largely depend on the solid properties of their precursors. Precipitation in fast contacting mixers of two precursors, boehmite and $\mathrm{NH}_{4}$-dawsonite, were investigated in order to obtain different and enhanced solid features. The mixing devices, a sliding surface mixing device (SSMD) and a rotorstator mixer (RSM), were operated continuously. Micromixing was characterized by using a competitive parallel reaction system (iodide-iodate). It was possible to achieve micromixing time from 1 to $200 \mathrm{~ms}$ according to the type of mixer and the operating conditions. The micromixing times assessed experimentally are in correct agreement with the theoretical ones. For boehmite precursor, the micromixing time had not a decisive influence on the crystallite size. Better control of the particle surface area was obtained considering the shear rate level, maybe due to a disordered aggregation. Conversely, reduction of the crystallite size with a decrease of the micromixing time was observed with $\mathrm{NH}_{4}$-dawsonite. A possible explanation lies in a higher local supersaturation, leading to a more intense primary nucleation. Moreover, it was possible to adjust the pore volume of the $\mathrm{NH}_{4}$-dawsonite's aggregates with the operating conditions to quite a large extent (0.2 up to $\left.0.8 \mathrm{~cm}^{3} \cdot \mathrm{g}^{-1}\right)$.
\end{abstract}

Keywords: Precipitation, boehmite, $\mathrm{NH}_{4}$-dawsonite, micromixing, fast-contacting mixer, iodide-iodate reaction

\section{Introduction}

Precipitation is a complex phenomenon which consists of mechanisms (nucleation, growth, aggregation...) depending on many factors. However, the establishment of the supersaturation is essential for a good control of the process, as it determines both nucleation and growth rates (Mersmann, 1999). As precipitation of sparingly soluble materials is generally associated with very fast reactions, the solid properties can be strongly influenced by mixing quality (Bałdyga et al., 2005). The importance of controlling the mixing during the precipitation is due to the difference between the mixing time scales and the various precipitation mechanisms time scale (Claassen and Sandenbergh, 2007). Although both macromixing (mixing on the scale of the whole vessel) and micromixing (mixing on the molecular scale, via viscousconvective deformation then diffusion) (Bałdyga and Pohorecki, 1995) can affect the precipitation process in various ways and, therefore, the product quality (Claassen and Sandenbergh, 2007), only micromixing is likely to promote very high supersaturation levels. Indeed, only its characteristic time scale is low enough to be theoretically able to compete with the fast reactions time scales as well as the precipitation mechanisms ones (Schwarzer and Peukert, 2004).

Therefore, the choice of the mixing technology is particularly important. The most commonly used reactor for precipitation is the stirred tank reactor in batch or semi-batch configuration. However, this technology suffers from two important drawbacks: the specific power dissipated by the stirrer is not homogeneously distributed in the whole reactor (Franke and Mersmann, 1995), and, due to discontinuous operation, precipitation conditions change throughout the process (Santiago et al., 2006). Using fast contacting mixers in continuous configuration could allow a better 
supersaturation control thanks to a more efficient mixing (due to high levels of dissipated power in a confined mixing zone), while maintaining quasi-constant precipitation conditions throughout the process, once the steady state is reached.

In the case of classical alumina precursors, such as boehmite $(\mathrm{AlOOH})$, it is well known that the textural properties of the initial precipitated precursor will condition and limit the textural properties of the final alumina-based catalyst support (Euzen et al., 2002). A better control of the precursor textural properties during the precipitation could thus lead to original properties on the final support. Moreover, this reasoning could also apply on ammonium dawsonite (also called ammonium aluminium carbonate hydroxide or $\mathrm{AACH}$, with formula $\mathrm{NH}_{4} \mathrm{Al}(\mathrm{OH})_{2} \mathrm{CO}_{3}$ ), an alternative precursor for the preparation of alumina-based catalyst supports (Ali et al., 2005). Influence of several parameters on the product properties have been studied so far: reactants (Shin et al., 2014), contacting mode (Dubert et al., 2011; Hu et al., 2012; Ma et al., 2001; Santiago et al., 2006), pH (C. Liu et al., 2012; H. Liu et al., 2012), molar ratio (Hu et al., 2012; Vogel et al., 1984), alternative medias (Duan et al., 2013; C. Liu et al., 2012)... However, influence of the micromixing time on the $\mathrm{NH}_{4}-$ dawsonite textural properties has, to our knowledge, never been investigated.

With this work, we present a comparative study of two different alumina precursors, boehmite and $\mathrm{NH}_{4}$-dawsonite, prepared by precipitation in two fast contacting mixers operated continuously: a sliding surface mixing device (SSMD) and a rotor-stator mixer (RSM). First, micromixing will be characterized in both mixers. Then, the influence of the micromixing time on the precursor properties will be assessed. This work is a partial reproduction of the $\mathrm{PhD}$ dissertation of Lafficher (2016), in which more detailed information can be found. It complements previous studies on boehmite precipitation with SSMD technology (Rousseaux et al., 2000) and $\mathrm{NH}_{4}$-dawsonite precipitation with $\mathrm{RSM}$ technology (Santiago et al., 2006).

\section{Experimental}

\subsection{Fast-contacting mixers}

The SSMD (Figure 1a) was designed based on the device presented by Rousseaux et al. (1999). It consists of a stainless steel cylindrical chamber in which is located a $120-\mathrm{mm}$ large rotating disc. The height $\mathrm{h}$ between the disc and the chamber flat bottom can be adjusted between 1 and $3 \mathrm{~mm}$. Reactants were injected in the confined mixing zone under the disc through a central feed tube (reactant a) and four lateral symmetrical feed tubes (reactant b), situated at equal distance $\mathrm{r}=40 \mathrm{~mm}$ from the center. The process parameters (disc rotation speed $\mathrm{N}$, total flowrate $\mathrm{Q}$, height $\mathrm{h}$ between the disc and the bottom of the reactor) were operated in the following ranges:

- $\quad \mathrm{N}: 160-2000 \mathrm{rpm}$

- $\quad$ Q: $200-2400 \mathrm{~mL} \cdot \mathrm{min}^{-1}$

- $\mathrm{h}: 1-3 \mathrm{~mm}$

The RSM (Figure 1b) used in this study is a DK40 from CAT, equipped with a double feed system. The rotor radius is $r_{R}=16.5 \mathrm{~mm}$ and the gap between rotor and stator is $\mathrm{e}=1 \mathrm{~mm}$. The process parameters (rotor rotation speed $\mathrm{N}$, total flowrate Q) were operated in the following ranges:

- $\quad \mathrm{N}: 2500-9000 \mathrm{rpm}$

- $\quad \mathrm{Q}: 300-1000 \mathrm{~mL} \cdot \mathrm{min}^{-1}$

Both mixers were operated in continuous mode. 


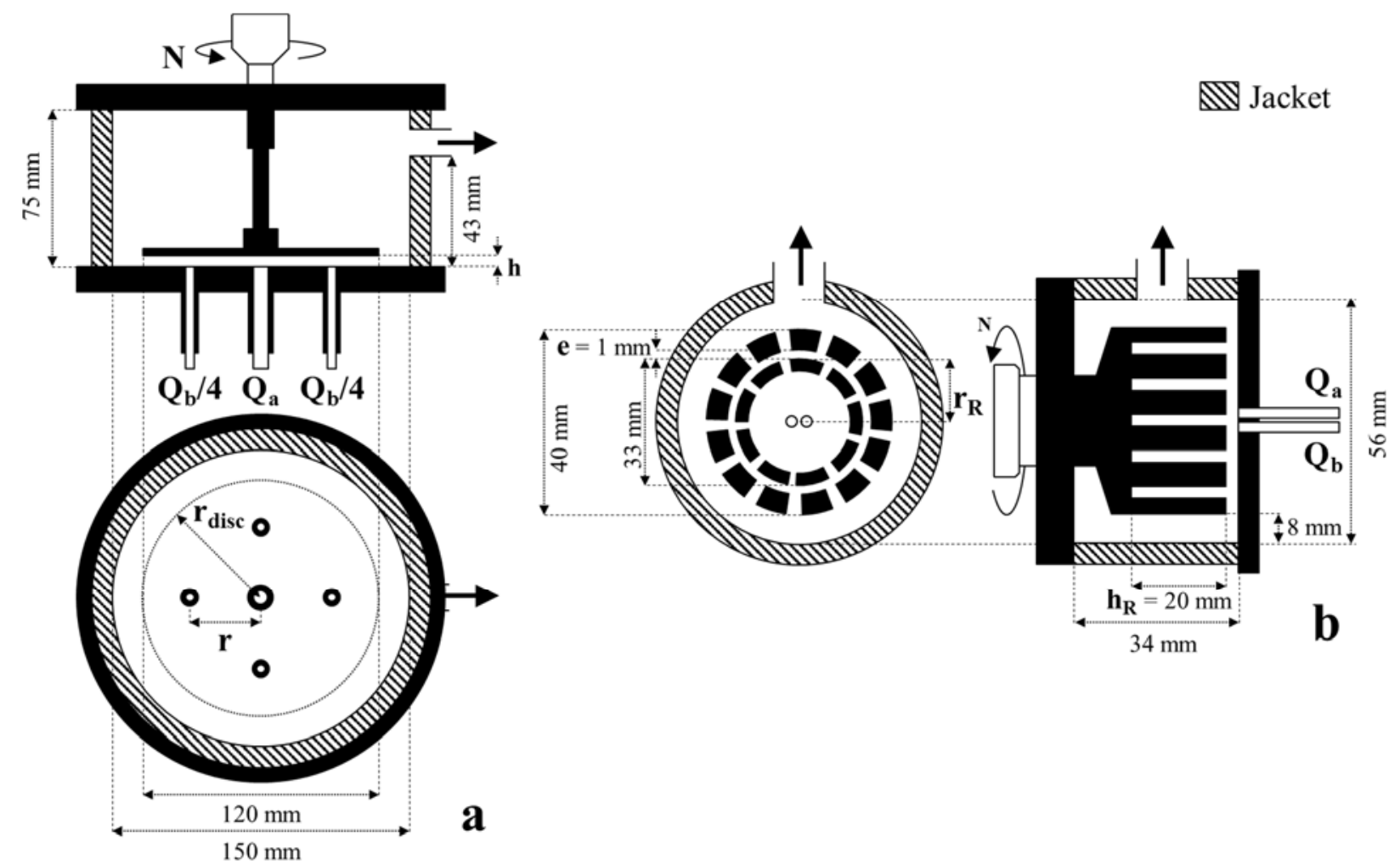

Figure 1. Schematic representation of investigated fast contacting mixers: front and bottom views of the SSMD (a), and front and profile views of the RSM (b).

\subsection{Micromixing characterization}

\subsubsection{Test reaction}

The iodide-iodate reaction system, implemented in this work, was proposed by Villermaux et al. (1992) and then essentially developed later (Fournier et al., 1996a, 1996b; Guichardon et al., 2000; Guichardon and Falk, 2000) to assess the micromixing intensity within various mixing technologies. This method is based on a competitive parallel reactions system: a quasi-instantaneous neutralization reaction (i) $\left(\mathrm{k}_{(\mathrm{i})}=10^{11} \mathrm{~L} \cdot \mathrm{mol}^{-1} \cdot \mathrm{s}^{-1}\right.$ at $25^{\circ} \mathrm{C}$ ) and a fast redox reaction (ii) (Dushman reaction, $\mathrm{k}_{(\mathrm{ii})}=\mathrm{f}(\mathrm{I})$ with $\mathrm{I}$ being the ionic strength). The iodine formed reacts immediately with iodide ions to yield triiodide ions, according to the quasi-instantaneous equilibrium (iii) $\left(\mathrm{k}_{(\mathrm{iii})}^{+}=5 \cdot 6 \cdot 10^{9} \mathrm{~L} \cdot \mathrm{mol}^{-1} \cdot \mathrm{s}^{-1}\right.$ and $\mathrm{k}_{\text {(iii) }}^{-}=7.5 \cdot 10^{9} \mathrm{~s}$ ${ }^{1}$ at $25^{\circ} \mathrm{C}$ ). The concentration of the triiodide ions can be measured by spectrophotometric absorption.

$\mathrm{H}_{2} \mathrm{BO}_{3}^{-}+\mathrm{H}^{+} \rightleftharpoons \mathrm{H}_{3} \mathrm{BO}_{3} \quad$ Quasi instantaneous reaction

$5 \mathrm{I}^{-}+\mathrm{IO}_{3}^{-}+6 \mathrm{H}^{+} \rightleftharpoons 3 \mathrm{I}_{2}+3 \mathrm{H}_{2} \mathrm{O} \quad$ Fast reaction

$\mathrm{I}_{2}+\mathrm{I}^{-} \rightleftharpoons \mathrm{I}_{3}^{-} \quad$ Quasi instantaneous equilibrium

Under perfect micromixing conditions, the injected acid is instantaneously dispersed in the reactive medium and consumed by borates according to reaction (i), which is infinitely faster than reaction (ii). Otherwise, the injected acid is consumed competitively by reactions (i) and (ii). The iodine selectivity is thus a good indicator of the fluid segregation state and the micromixing efficiency.

The segregation index $\mathrm{X}_{\mathrm{S}}$ (Eq. (1)) is used to quantify this segregation state. It can be defined as the value representing the actual yield of the undesired product $\mathrm{Y}$, compared with the maximum yield of the undesired product $\mathrm{Y}_{\mathrm{ST}}$ formed under conditions where the micromixing is infinitely slow and total segregation occurs. In case of perfect mixing, no iodine is formed and $X_{S}=0$. On the contrary, in case of total segregation, $X_{S}=1$. 
$X_{S}=\frac{Y}{Y_{S T}}$

$\mathrm{Y}$ and $\mathrm{Y}_{\mathrm{ST}}$ were calculated with the following expressions:

$Y=\frac{2\left(n_{I_{2}}+n_{I_{3}^{-}}\right)}{n_{H^{+}}}$

$Y_{S T}=\frac{6\left[I O_{3}^{-}\right]_{0}}{\left[\mathrm{H}_{2} \mathrm{BO}_{3}^{-}\right]_{0}+6\left[I O_{3}^{-}\right]_{0}}$

with the total injected acid quantity $\mathrm{n}_{\mathrm{H}+0}$, and the initial iodate ion and borate ion concentrations, respectively $\left[\mathrm{IO}_{3}{ }^{-}\right]_{0}$ and $\left[\mathrm{H}_{2} \mathrm{BO}_{3}^{-}\right]_{0}$.

The micromixedness ratio $\alpha$ (Eq. (4)) is another indicator used to characterize the micromixing efficiency. It can be defined as the value representing the perfectly mixed volume $V_{P M}$, compared with the totally segregated volume $V_{S T}$. $X_{S}$ and $\alpha$ were determined according to the procedure proposed by Guichardon and Falk (2000).

$\alpha=\frac{V_{P M}}{V_{S T}}=\frac{1-X_{S}}{X_{S}}$

In order to ensure that the measured triiodide ion concentration can only be formed due to the segregation of the fluid associated with the micromixing efficiency of the reactor, it is important to take care that the mean $\mathrm{pH}$ value is higher than the iodine dismutation $\mathrm{pH}\left(\mathrm{pH}^{*}\right)$; otherwise, iodine would be naturally formed even in the absence of acid aggregates (Guichardon and Falk, 2000). However, at strong basic $\mathrm{pH}$ much greater than $\mathrm{pH}^{*}$, the iodine formed is thermodynamically unstable and its dissociation can be non-negligible. In order to prevent this effect, the average working $\mathrm{pH}$ must be as close as possible to $\mathrm{pH}^{*}$ (generally $\mathrm{pH} \leq 9.7$ ) (Guichardon, 1996).

\subsubsection{Determination of the micromixedness ratio $\alpha$}

Two solutions, I and H, were prepared following the procedure proposed by Guichardon and Falk (2000). Choice of the concentrations, flowrate ratio and molar ratios (Tables 1 and 2) was adapted from the protocol proposed in the same work for continuous mixers.

Table 1. Initial concentration of the reactants.

\begin{tabular}{cccccc}
\hline \multicolumn{3}{c}{ Solution I } & & Solution $H$ \\
\cline { 1 - 3 } \cline { 1 - 1 } $\begin{array}{c}{\left[\mathrm{H}_{3} \mathrm{BO}_{3}\right]} \\
\left(\mathrm{mol}^{-1}\right)\end{array}$ & $\begin{array}{c}{[\mathrm{NaOH}]} \\
\left(\mathrm{mol} . \mathrm{L}^{-1}\right)\end{array}$ & $\begin{array}{c}{[\mathrm{KI}]} \\
\left(\mathrm{mol} . \mathrm{L}^{-1}\right)\end{array}$ & $\begin{array}{c}{\left[\mathrm{KIO}_{3}\right]} \\
\left(\mathrm{mol}^{-1}\right)\end{array}$ & & $\begin{array}{c}{\left[\mathrm{H}_{2} \mathrm{SO}_{4}\right]} \\
\left(\mathrm{mol} . \mathrm{L}^{-1}\right)\end{array}$ \\
\hline 0,3636 & 0,1818 & 0,02334 & 0,00468 & & 0,08 \\
\hline
\end{tabular}

Table 2. Initial concentrations, flowrate ratio and molar ratios for solutions I and H used in SSMD and RSM.

\begin{tabular}{|c|c|c|c|c|c|}
\hline \multicolumn{2}{|c|}{ Solution I } & Solution $H$ & & $\mathrm{n}_{\mathrm{H}_{2} \mathrm{BO}_{3}^{-}}$ & $\mathrm{n}_{\mathrm{I}_{2} \text { potential }}$ \\
\hline $\begin{array}{l}{\left[\mathrm{H}_{2} \mathrm{BO}_{3}{ }^{-}\right]} \\
\left(\mathrm{mol}^{-1} \mathrm{~L}^{-1}\right)\end{array}$ & $\begin{array}{l}{\left[\mathrm{I}_{2}\right]_{\text {potential }}} \\
\left(\mathrm{mol} . \mathrm{L}^{-1}\right)\end{array}$ & $\begin{array}{c}{\left[\mathrm{H}^{+}\right]_{0}} \\
\left(\mathrm{~mol} . \mathrm{L}^{-1}\right)\end{array}$ & $\mathrm{K}^{-} \overline{\mathrm{Q}_{\mathrm{H}}}$ & $\mathrm{n}_{\mathrm{H}_{0}^{+}}$ & $\mathrm{n}_{\mathrm{H}^{+}}{ }_{0}$ \\
\hline 0,1818 & 0,0140 & 0,16 & 20 & 22,725 & 1,751 \\
\hline
\end{tabular}

The following procedure was adopted for each of the SSMD and RSM: 


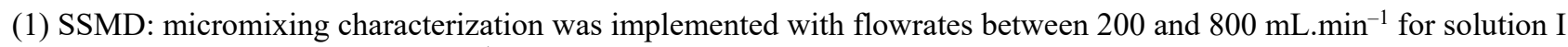
and between 10 and $40 \mathrm{~mL} \cdot \mathrm{min}^{-1}$ for solution H. Solution I was injected in the central feed tube. As the four lateral feed tubes are symmetrical, solution $\mathrm{H}$ was injected in only one radial feed tube, the other three being blocked. Influence on micromixing of the disc rotation speed $\mathrm{N}$, the total flowrate $\mathrm{Q}$ and the height $\mathrm{h}$ between the disc and the bottom of the reactor were studied for the following values:

- $\quad \mathrm{N}=150 ; 300 ; 500 ; 1000 ; 1500 ; 2000 \mathrm{rpm}$

- $\mathrm{Q}=210 ; 315 ; 420 ; 840 \mathrm{~mL} \cdot \mathrm{min}^{-1}$

- $\mathrm{h}=1 ; 2 ; 3 \mathrm{~mm}$

One minute after the start of the injection, several samples were collected at regular intervals and analyzed within the five minutes following the sampling.

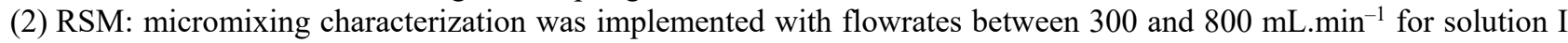
and between 15 and $40 \mathrm{~mL} \cdot \mathrm{min}^{-1}$ for solution $\mathrm{H}$. The two central feed tubes enable the injection of both solutions I and $\mathrm{H}$ at the center of the rotor. Influence on micromixing of the rotor rotation speed $\mathrm{N}$ and the total flowrate $\mathrm{Q}$ were studied for the following values:

- $\quad \mathrm{N}=2500 ; 5500 ; 7000 ; 9000 \mathrm{rpm}$

- $\mathrm{Q}=315 ; 630 ; 840 \mathrm{~mL} \cdot \mathrm{min}^{-1}$

The RSM cell was first filled with distilled water to avoid the rotor running dry at the beginning of the injection. The equivalent of ten times the RSM chamber volume was injected, before several samples were collected at regular intervals and analyzed within the five minutes following the sampling. It was verified that starting the sampling collection at $\mathrm{t}=10 \tau$ (with $\tau$ being the mean residence time in the RSM) was sufficient to avoid a dilution influence on the absorbance measurements (no significant variation $(<7 \%)$ of the micromixedness ratio $\alpha$ for each given experiment, when measured in the time range $10 \tau \leq \mathrm{t} \leq 40 \tau)$.

All the analyzed samples met the $\mathrm{pH}$ criterion $\left(\mathrm{pH}^{*}<\mathrm{pH}<9,7\right)$ and presented a temperature between 20 and $25^{\circ} \mathrm{C}$.

\subsection{Precipitation protocols}

\subsubsection{Synthesis of boehmite}

Reagent grade aluminium sulphate (Univar, reactant a) and sodium aluminate (Sigma-Aldrich, reactant b) were used as starting materials without further purification. Boehmite was precipitated by simultaneous addition of an aluminium sulphate solution $\left(\mathrm{C}_{\mathrm{a}}=0.27 \mathrm{~mol} . \mathrm{L}^{-1}\right.$ and 0.09 mol.L $\mathrm{L}^{-1}$, respectively in SSMD and RSM) and a sodium aluminate solution $\left(\mathrm{C}_{\mathrm{b}}=0.83 \mathrm{~mol} . \mathrm{L}^{-1}\right.$ and $0.28 \mathrm{~mol} . \mathrm{L}^{-1}$, respectively in SSMD and RSM):

$$
\mathrm{Al}_{2}\left(\mathrm{SO}_{4}\right)_{3}+6 \mathrm{NaAl}(\mathrm{OH})_{4} \rightarrow 8 \mathrm{AlOOH}+3 \mathrm{Na}_{2} \mathrm{SO}_{4}+8 \mathrm{H}_{2} \mathrm{O}
$$

The molar ratio $\mathrm{R}_{\mathrm{b} / \mathrm{a}}$ (defined as the molar ratio of $\mathrm{NaAl}(\mathrm{OH})_{4}$ over $\mathrm{Al}_{2}\left(\mathrm{SO}_{4}\right)_{3}$ ) was 4.0 , and the suspension temperature was controlled at $60 \pm 2{ }^{\circ} \mathrm{C}$. Synthesis in SSMD were set up at pH $9.6 \pm 0.3$ and at final solid phase concentration $\mathrm{C}_{\mathrm{s}}=42.4 \mathrm{~g} . \mathrm{L}^{-1}$. Synthesis in RSM were set up at $\mathrm{pH} 8.8 \pm 0.3$ and at final solid phase concentration $\mathrm{C}_{\mathrm{s}}=14.1 \mathrm{~g} . \mathrm{L}^{-1}$. The various operating parameters investigated are given in Table 3 . After the synthesis, the suspension was filtered and washed five times using hot water in order to minimize the impurities content $\left(\mathrm{Na}^{+}\right.$and $\left.\mathrm{SO}_{4}^{2-}\right)$. Then, the filtration cake was dried at $120^{\circ} \mathrm{C}$ overnight and ground. The obtained boehmite dried precursor was labeled as $\mathrm{B} / \mathrm{xxx}$, $\mathrm{xxx}$ corresponding to the mixer used (SSMD or RSM).

\subsubsection{Synthesis of $\mathrm{NH}_{4}$-dawsonite}

Reagent grade aluminium nitrate (Alfa Aesar, reactant a) and carbonate ammonium (Alfa Aesar, reactant b) were used as starting materials without further purification. $\mathrm{NH}_{4}$-dawsonite was precipitated by simultaneous addition of an aluminium nitrate solution $\left(\mathrm{C}_{\mathrm{a}}=1.2 \mathrm{~mol} \cdot \mathrm{L}^{-1}\right.$ in both SSMD and RSM) and a carbonate ammonium solution $\left(\mathrm{C}_{\mathrm{b}}=2.0 \mathrm{~mol} \cdot \mathrm{L}^{-1}\right.$ in both SSMD and RSM):

$$
\mathrm{Al}\left(\mathrm{NO}_{3}\right)_{3}+2\left(\mathrm{NH}_{4}\right)_{2} \mathrm{CO}_{3}+\mathrm{H}_{2} \mathrm{O} \rightarrow \mathrm{NH}_{4} \mathrm{Al}(\mathrm{OH})_{2} \mathrm{CO}_{3}+\mathrm{CO}_{2}+3 \mathrm{NH}_{4} \mathrm{NO}_{3}
$$

The molar ratio $\mathrm{R}_{\mathrm{b} / \mathrm{a}}$ (defined as the molar ratio of $\left(\mathrm{NH}_{4}\right)_{2} \mathrm{CO}_{3}$ over $\left.\mathrm{Al}\left(\mathrm{NO}_{3}\right)_{3}\right)$ was 8.0, and the suspension temperature was controlled at $60 \pm 2{ }^{\circ} \mathrm{C}$. Synthesis in both SSMD and RSM were set up at pH 7.9 \pm 0.2 and at final solid phase concentration $\mathrm{C}_{\mathrm{s}}=28.8 \mathrm{~g} . \mathrm{L}^{-1}$. The various operating parameters investigated are given in Table 5. After the synthesis, the suspension was filtered and washed once with hot water. Then the cake was dried at $120^{\circ} \mathrm{C}$ overnight and ground. The obtained $\mathrm{NH}_{4}$-dawsonite dried precursor was labeled as $\mathrm{D} / \mathrm{xxx}, \mathrm{xxx}$ corresponding to the mixer used (SSMD or RSM). 


\subsection{Characterization methods}

For micromixing characterization, triiodide ion concentration was determined with a double beam spectrophotometer UV/Vis Cary 4G, according to the Beer-Lambert's law. Absorbance $\mathrm{D}_{\lambda}$ was measured at a wavelength $\lambda=353 \mathrm{~nm}$ (absorption maxima), with a quartz cell thickness of $1 \mathrm{~cm}$ and a molar extinction coefficient $\varepsilon_{\lambda}$ determined as $2620 \mathrm{~m}^{2} \cdot \mathrm{mol}^{-1}$.

The crystal phase identification was done by powder X-ray diffraction (XRD). Data were collected on a PANalytical $\mathrm{X}^{\prime}$ Pert Pro $\theta-\theta$ diffractometer in Bragg-Brentano geometry, using filtered $\mathrm{Cu} \mathrm{K} \alpha$ radiation and a graphite secondarybeam monochromator. Diffraction intensities were measured, at room temperature, by scanning from 5 to $72^{\circ}$ with a step size of $0.033^{\circ}(2 \theta)$. Average crystallite size L was determined using Scherrer's equation, applied on the crystallographic planes (120) and (111), respectively for boehmite and $\mathrm{NH}_{4}$-dawsonite.

The nitrogen adsorption-desorption isotherms were collected at $77 \mathrm{~K}$ using an adsorption analyzer Micromeritics ASAP 2420. Boehmite and $\mathrm{NH}_{4}$-dawsonite samples were previously degassed in vacuum for $3 \mathrm{~h}$ at $250{ }^{\circ} \mathrm{C}$ and $6 \mathrm{~h}$ at $80^{\circ} \mathrm{C}$, respectively. The specific surface area $\left(\mathrm{S}_{\mathrm{BET}}\right)$ was determined by the BET method in pressure domain $0.05 \leq \mathrm{P} / \mathrm{P}_{0} \leq 0.35$. Pore size distributions (PSD) were calculated from the desorption branches of the isotherms using the $\mathrm{BJH}$ model. The mean pore diameter $\left(\mathrm{D}_{\mathrm{p}}\right)$ corresponds to the maximum of the pore size distribution (i.e. its modal value). When the PSD is not monomodal, we report two (or more) $\mathrm{D}_{\mathrm{p}}$ values corresponding to the two (or more) observed local maxima. Pore volume $\left(\mathrm{V}_{\mathrm{p}}\right)$ was calculated from the adsorbed volume of gas $\mathrm{V}_{\text {ads }}$ at the higher relative pressure $\left(\mathrm{P} / \mathrm{P}_{0} \approx\right.$ 0.99).

\section{Results and discussion}

\subsection{Micromixing characterization of continuous fast-contacting mixers}

\subsubsection{Determination of micromixing times $t_{m}$}

Contrary to the micromixedness ratio $\alpha$, which can be determined experimentally, the micromixing time $t_{m}$ can only be estimated by micromixing models. According to the procedure described in Fournier et al. (1996a) and Rousseaux et al. (1999), an incorporation model was employed to calculate the theoretical value of $\alpha$ for each given micromixing time value and for the initial reagent concentrations used experimentally in this work. The micromixing time appeared to be proportional to $\alpha^{-\mathrm{n}}$, even though the proportional coefficient and the power $\mathrm{n}$ can vary according to the magnitude of $\alpha$. In order to facilitate the numerical treatment of the experimental data, we arbitrarily chose to express the results of Figure 2 in the form of three equations obtained by regression analysis:

$$
\begin{array}{ll}
4<\alpha<10 & t_{m}=2.1024 \cdot \alpha^{-1.459} \\
10<\alpha<60 & t_{m}=0.9436 \cdot \alpha^{-1.117} \\
60<\alpha<290 & t_{m}=0.6412 \cdot \alpha^{-1.021}
\end{array}
$$

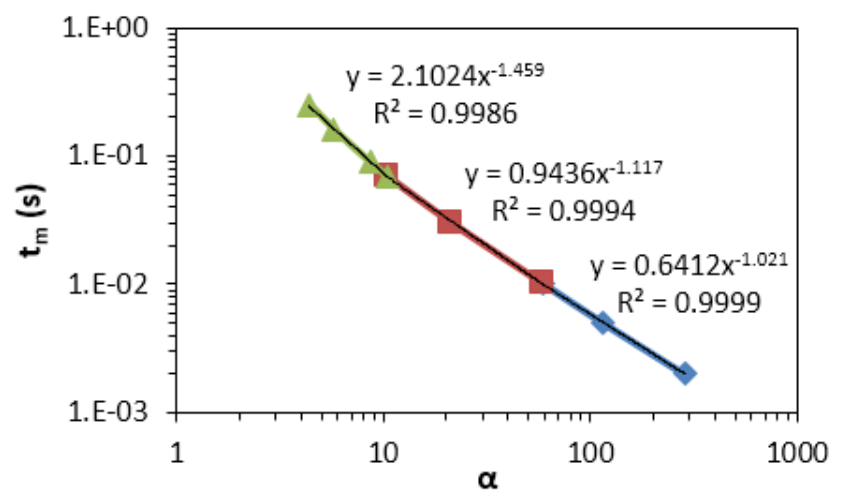

Figure 2. Micromixing time $t_{\mathrm{m}}$ against micromixedness ratio $\alpha$.

Practically, after having measured an experimental micromixedness ratio $\alpha$ in one of the studied mixing devices thanks to the iodide-iodate method, this experimental value was reported on Figure 2 to determine the corresponding micromixing time, as described in Guichardon and Falk (2000). Since this latter is obtained thanks to experimental measurements, it is thereafter noted as $\mathrm{t}_{\mathrm{m}(\mathrm{exp}) \text {. }}$ 


\subsubsection{SSMD characterization}

As a first step, we evaluated the respective influence of the studied parameters $(\mathrm{N}, \mathrm{Q}, \mathrm{h})$ on the micromixing time. We observed that increasing the disc rotation speed or the total flowrate generally led to a decrease of the micromixing time (Lafficher, 2016), in accordance with the trend previously reported by Rousseaux et al. (1999). The reason is that both $\mathrm{N}$ and Q contribute to the specific power dissipation into the fluid. On the contrary, increasing the disc height led to an increase of the micromixing time, which is consistent with an increase of the confined mixing zone volume. However, it seemed that the impact of this parameter is lowered when the disc rotation speed and the total flowrate are high enough $\left(\mathrm{N}>1000 \mathrm{rpm}\right.$ and $\left.\mathrm{Q}>420 \mathrm{~mL} \cdot \mathrm{min}^{-1}\right)$.

In a second phase, we compared our experimental micromixing time values with the theoretical expressions developed by Rousseaux et al. (1999). According to this work, two cases can be distinguished depending on whether the flow is laminar ( $\operatorname{Re}<1.10^{5}$, see Eq. (8)) or turbulent ( $\operatorname{Re}>3.10^{5}$, see Eq. (9)). For intermediate rotational Reynold numbers, given by Eq. (10), we considered the average value of both expressions (8) and (9).

$$
\begin{aligned}
& t_{m(\text { theo })}=\frac{1}{\sqrt{0.0090\left(\frac{r N}{h}\right)^{2}+0.065\left(\frac{Q}{r}\right)^{2} \frac{1}{h^{4}}}} \\
& t_{m(\text { theo })}=\frac{1}{\sqrt{0.37(r N)^{11 / 4} \frac{1}{h^{5 / 4}}+490\left(\frac{Q}{r}\right)^{14 / 5} \frac{1}{h^{4}}}} \\
& \operatorname{Re}=\frac{\omega r^{2}}{v}=\frac{2 \pi N r^{2}}{v}
\end{aligned}
$$

Figure 3 shows a correct agreement between experimental and theoretical micromixing times in SSMD in the range $10-150 \mathrm{~ms}$. However, it was not possible to reach experimental micromixing time below $10 \mathrm{~ms}$, despite the choice of parameters theoretically adapted. Likewise, experimental micromixing time could hardly be increased above $150 \mathrm{ms,}$, and uncertainty was particularly high in this range. Consequently, the highest micromixing time reached with the SSMD was $180 \mathrm{~ms}$. However, it must be noted that the theoretical expressions developed by Rousseaux et al. (1999) are based on experimental measurements carried out in the $10-100 \mathrm{~ms}$ range, which could explain in some ways the differences observed outside this range.

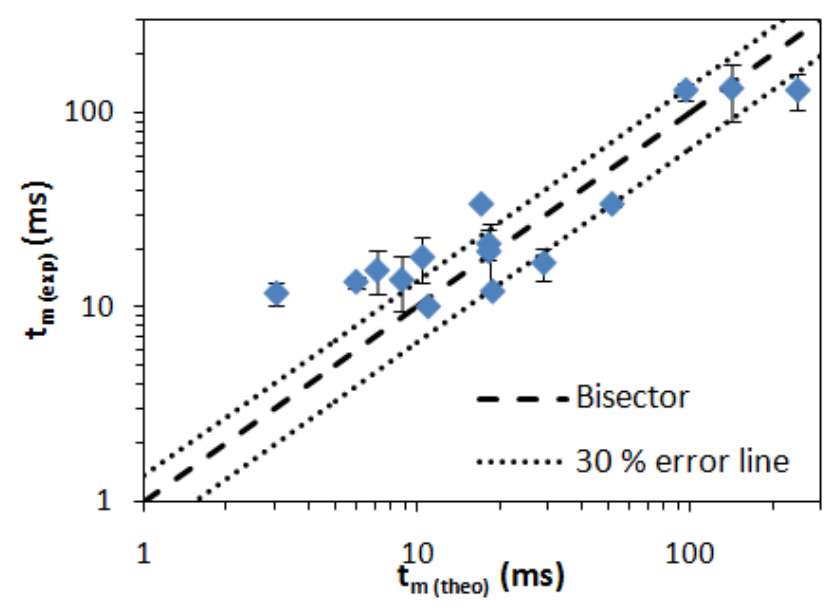

Figure 3. Experimental micromixing time against theoretical micromixing time (SSMD).

\subsubsection{RSM characterization}

As a first step, we evaluated the respective influence of the studied parameters $(\mathrm{N}, \mathrm{Q})$ on the micromixing time. We observed that increasing the rotor rotation speed from 2500 to $9000 \mathrm{rpm}$ led to a decrease of the micromixing time from 6 to $1 \mathrm{~ms}$ (Lafficher, 2016). However, the micromixing time was not affected by a total flowrate variation between 315 and $840 \mathrm{~mL} \cdot \mathrm{min}^{-1}$. 
In a second phase, we compared our experimental micromixing time values with the theoretical expression (11). The dissipated specific power (Eq. (12)) was expressed at first approximation by considering the RSM shear rate to be equivalent to the one of a Couette system in which the internal cylinder would be mobile while the external cylinder would be stationary (Renouf, 2000). This expression does not take into account the influence of the flowrate, as it should be the case for a continuous RSM (Kowalski, 2009). However, as mentioned above, we observed that micromixing time did not seem to be affected by the flowrate in the studied conditions. Moreover, this expression considers the rotor and the gap dimensions and could thereby be used for RSM of different sizes, which is not the case of most of the correlations in the literature (Bourne and Studer, 1992).

$$
\begin{aligned}
& t_{m(\text { theo })}=17.2 \sqrt{\frac{\nu}{\varepsilon}} \\
& \varepsilon=\frac{v \omega^{2} r_{R}^{2}}{e^{2}}
\end{aligned}
$$

Figure 4 shows a relatively correct agreement between experimental and theoretical micromixing times in RSM, considering that a $60 \%$ error is acceptable in the limited studied range, since the model used here was not specifically developed for our mixing device. What is interesting here is that the RSM, contrary to the SSMD, is able to reach micromixing times in the range of some milliseconds to one millisecond. It thus can be noted that the inability of the SSMD to reach such an experimental micromixing time range does not seem to be due to an inappropriate choice of concentration for the iodide-iodate reaction system.

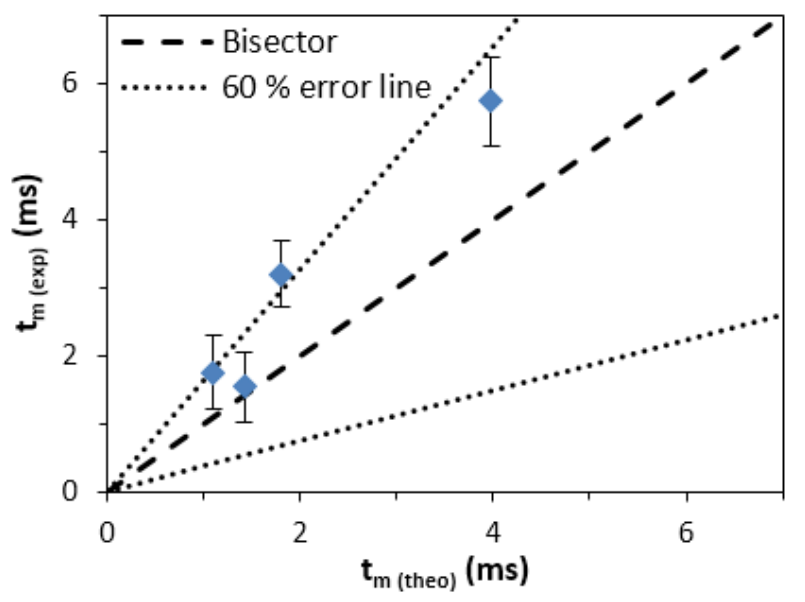

Figure 4. Experimental micromixing time against theoretical micromixing time (RSM).

\subsection{Experimental study of precipitation in continuous fast-contacting mixers}

The micromixing quality in both the SSMD and the RSM was characterized in the first part of this study, and a correct agreement between micromixing time theoretical expressions and experimental values was obtained. Micromixing times in this precipitation study will thus be calculated according to Eq. (8) and (9) for SSMD (but considering a lower limit of $10 \mathrm{~ms}$ and an upper limit of $180 \mathrm{~ms}$ ), and Eq. (11) and (12) for RSM. However, it should be kept in mind that the micromixing conditions during a precipitation experiment may differ in some ways from that characterized with a chemical test reaction, since the latter generally imply working with specific flowrates or flowrate distributions.

\subsubsection{Boehmite precipitation}

Boehmite was precipitated in the SSMD and the RSM at different micromixing times (see Table 3). More diluted feed solutions were used with the RSM due to operability issues at higher concentrations (gel formation). However, it was verified that concentration had no influence on boehmite properties in the range considered (Lafficher, 2016). Powder XRD analysis confirmed the presence of a single crystalline phase corresponding to boehmite (ICDD 21-1307) and the textural properties were assessed by $\mathrm{N}_{2}$ physisorption (see Table 4). The reproducibility of boehmite precipitations in both SSMD and RSM has been investigated by carrying out two or three identical runs for some sets of parameters. Globally, the uncertainties for boehmite's crystallite size, specific surface area and pore volume were respectively below $9 \%, 5 \%$ and $7 \%$. 
Table 3. Operating parameters investigated for boehmite precipitation in the SSMD and the RSM.

\begin{tabular}{|c|c|c|c|c|c|c|c|c|c|c|c|}
\hline Ref. & $\begin{array}{c}\mathrm{C}_{\mathrm{a}} \\
\left(\mathrm{mol} . \mathrm{L}^{-1}\right)\end{array}$ & $\begin{array}{c}\mathrm{Cb}_{\mathrm{b}} \\
\left(\mathrm{mol} \cdot \mathrm{L}^{-1}\right)\end{array}$ & $\mathrm{R}_{\mathrm{b} / \mathrm{a}}$ & $\begin{array}{c}\mathrm{Q}_{\mathrm{a}} \\
\left(\mathrm{mL} \cdot \mathrm{min}^{-1}\right)\end{array}$ & $\begin{array}{c}\mathrm{Qb} \\
\left(\mathrm{mL} \cdot \mathrm{min}^{-1}\right)\end{array}$ & $\begin{array}{c}\mathrm{N} \\
(\mathrm{rpm})\end{array}$ & $\begin{array}{c}\mathrm{r} \\
(\mathrm{mm})\end{array}$ & $\begin{array}{c}\mathrm{h} \\
(\mathrm{mm})\end{array}$ & $\begin{array}{c}\mathrm{C}_{\mathrm{s}} \\
\left(\mathrm{g} \cdot \mathrm{L}^{-1}\right)\end{array}$ & $\begin{array}{l}\mathrm{t}_{\mathrm{m}} \text { (theo) } \\
(\mathrm{ms})\end{array}$ & $\begin{array}{c}\dot{\gamma} \\
\left(\mathrm{s}^{-1}\right)\end{array}$ \\
\hline $\mathrm{B} / \mathrm{SSMD}(01)$ & 0.27 & 0.83 & 4 & 420.0 & $4 \times 138.2$ & 2000 & 40 & 1.0 & 42.4 & 10 & $8.4 .10^{3}$ \\
\hline $\mathrm{B} / \mathrm{SSMD}(02)$ & 0.27 & 0.83 & 4 & 420.0 & $4 \times 138.2$ & 200 & 40 & 1.0 & 42.4 & 10 & $8.4 .10^{2}$ \\
\hline $\mathrm{B} / \mathrm{SSMD}(03)$ & 0.27 & 0.83 & 4 & 84.0 & $4 \times 27.6$ & 200 & 40 & 1.0 & 42.4 & 41 & $8.4 .10^{2}$ \\
\hline B/SSMD(04) & 0.27 & 0.83 & 4 & 175.3 & $4 \times 57.7$ & 1400 & 40 & 1.5 & 42.4 & 16 & $3.9 .10^{3}$ \\
\hline $\mathrm{B} / \mathrm{SSMD}(05)$ & 0.27 & 0.83 & 4 & 175.3 & $4 \times 57.7$ & 600 & 40 & 2.5 & 42.4 & 60 & $1.0 .10^{3}$ \\
\hline $\mathrm{B} / \mathrm{SSMD}(06)$ & 0.27 & 0.83 & 4 & 151.1 & $4 \times 49.7$ & 280 & 40 & 3.0 & 42.4 & 150 & $3.9 .10^{2}$ \\
\hline $\mathrm{B} / \mathrm{SSMD}(07)$ & 0.27 & 0.83 & 4 & 86.4 & $4 \times 28.4$ & 160 & 40 & 3.0 & 42.4 & 180 & $2.2 .10^{2}$ \\
\hline $\mathrm{B} / \mathrm{RSM}(01)$ & 0.09 & 0.28 & 4 & 431.7 & 568.8 & 7000 & - & - & 14.1 & 1.4 & $1.2 .10^{4}$ \\
\hline $\mathrm{B} / \mathrm{RSM}(02)$ & 0.09 & 0.28 & 4 & 431.7 & 568.8 & 2500 & - & - & 14.1 & 4 & $4.3 \cdot 10^{3}$ \\
\hline
\end{tabular}

Table 4. Properties of boehmite precipitated in the SSMD and the RSM.

\begin{tabular}{|c|c|c|c|c|c|}
\hline \multirow{2}{*}{ Ref. } & \multicolumn{2}{|c|}{ Crystallite size } & \multirow{2}{*}{$\begin{array}{c}\text { SBET } \\
\left(\mathrm{m}^{2} \cdot \mathrm{g}^{-1}\right)\end{array}$} & \multirow{2}{*}{$\begin{array}{c}\mathrm{V}_{\mathrm{p}} \\
\left(\mathrm{cm}^{3} \cdot \mathrm{g}^{-1}\right)\end{array}$} & \multirow{2}{*}{$\begin{array}{c}\mathrm{D}_{\mathrm{p}} \\
(\mathrm{nm})\end{array}$} \\
\hline & $\mathrm{d}_{020}(\mathrm{~nm})$ & $\mathrm{d}_{120}(\mathrm{~nm})$ & & & \\
\hline $\mathrm{B} / \mathrm{SSMD}(01)$ & 2.7 & 3.1 & 362 & 0.32 & 3.8 \\
\hline B/SSMD(02) & 2.7 & 2.7 & 272 & 0.35 & 3.7 \\
\hline B/SSMD(03) & 2.5 & 2.5 & 285 & 0.31 & 3.7 \\
\hline B/SSMD(04) & 2.5 & 2.6 & 357 & 0.33 & 3.9 \\
\hline $\mathrm{B} / \mathrm{SSMD}(05)$ & 2.5 & 2.7 & 330 & 0.29 & 3.7 \\
\hline B/SSMD(06) & 2.6 & 2.9 & 318 & 0.29 & 3.7 \\
\hline B/SSMD(07) & 3.0 & 3.4 & 318 & 0.33 & 3.7 \\
\hline $\mathrm{B} / \mathrm{RSM}(01)$ & 2.4 & 2.6 & 382 & 0.37 & 3.7 \\
\hline $\mathrm{B} / \mathrm{RSM}(02)$ & 2.6 & 2.8 & 328 & 0.28 & 3.7 \\
\hline
\end{tabular}

Whatever the operating conditions, boehmite precipitated in fast contacting mixers exhibited a type IV isotherm (see Figure 5a), which is typical of mesoporous materials, and the mean pore diameter is centered between 3.7 and $3.9 \mathrm{~nm}$ (see Figure 5b). 

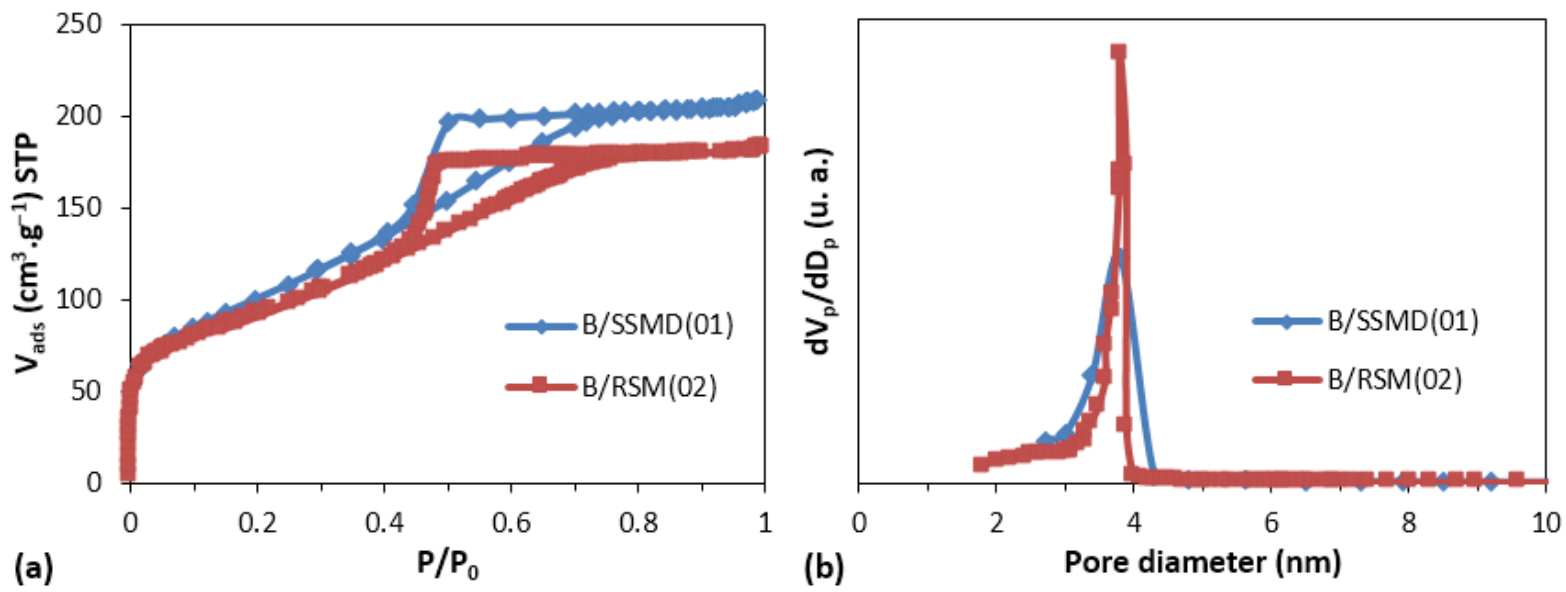

Figure 5. $\mathrm{N}_{2}$ adsorption-desorption isotherms (a) and pore size distributions (b) of boehmite obtained by precipitation in fast contacting mixers SSMD and RSM.

Figure 6 presents the evolution of the crystallite mean size with micromixing time for both contacting mixers. There is not a significant evolution of the crystallite size which remains in the range from 2.5 up to $3.4 \mathrm{~nm}$ and appears to be insensitive to the micromixing time. From a theoretical point of view, this result seems to be surprising since a reduction of the micromixing time may lead to an increase of the supersaturation level. A higher supersaturation may promote numerous and smaller crystallites due to a higher primary nucleation rate. Several hypotheses might be considered. First, the micromixing time were assessed in the absence of precipitation. The presence of numerous nanoparticles in the mixing zone due to intense primary nucleation may alter the micromixing time and the obtained supersaturation level. For a solid concentration of $42.4 \mathrm{~g} . \mathrm{L}^{-1}$, the volume fraction of particles is $1.3 \%$. The estimated interparticle distance is about $6 \mathrm{~nm}$ (Barnes et al., 1989). We could then consider that particle had interactions with its neighbors. These repulsive or attractive interactions between nanoparticles may promote locally an increase of the viscosity of a few orders of magnitude, even though the medium is slightly concentrated and the solvent viscosity low (Barnes et al., 1989). During trials, it was not possible to measure the rheological properties of the colloidal suspension in the mixing zone inside the mixers, but only of the slurries flowing out and containing particles already largely aggregated (few tens of microns). These slurries exhibited higher viscosities than the inlet flows, but this increase was at most one order of magnitude (from 3 up to 10 $\mathrm{mPa} . \mathrm{s}$ ) and not representative of a possible more important viscosity rise in the mixing zone. Some attempts to model the first moments of the precipitation were performed by using an interaction model (Aubry and Villermaux, 1975) (see details in Lafficher, 2016). This modelling shows that the supersaturation level is dependent on the micromixing time, as expected. Nevertheless, this dependency stops for micromixing time lower than a threshold. This threshold depends on viscosity. For instance, for a viscosity of $25 \mathrm{mPa}$.s, this threshold is about $200 \mathrm{~ms}$. Since the maximal micromixing time achieved was $180 \mathrm{~ms}$ in the SSMD, it could be assumed that such local viscosity was obtained in the mixing zone, preventing an increase of the supersaturation level, and consequently an effect on the crystallite size of boehmite. Kind (2002) has got another suggestion. The colloidal behavior of the primary particles caused the apparition of gelatinous regions acting like droplets and having an interfacial tension. The incorporation of reactants could be slower, leading to a higher micromixing time than the one estimated without the presence of nanoparticles. 


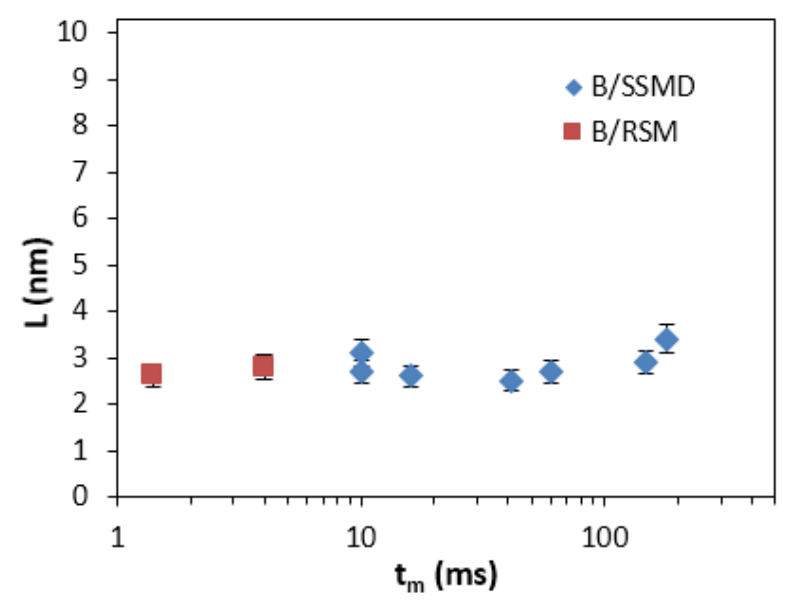

Figure 6. Average crystallite size evolution with micromixing time of boehmite precipitated in SSMD and RSM.

Figure 7 presents the influence of the micromixing time on the textural properties of boehmite samples precipitated in fast contacting mixers. In the absence of significant evolution of the crystallite size, the different materials exhibited a similar pore volume close to $0.3 \mathrm{~cm}^{3} \cdot \mathrm{g}^{-1}$ with variations lower than $0.1 \mathrm{~cm}^{3} \cdot \mathrm{g}^{-1}$. Contrary to the crystallite size and the pore volume, the specific surface area varies significantly from 270 to $380 \mathrm{~m}^{2} \cdot \mathrm{g}^{-1}$ with the micromixing time. Nevertheless, it is not obvious to notice a clear tendency, since the results are quite scattered in Figure $7 \mathrm{~b}$. The evolution of the specific surface area is better understood considering the shear rate level. Figure 8 shows that the specific surface area increases progressively with the shear rate, with variation of more than $100 \mathrm{~m}^{2} \cdot \mathrm{g}^{-1}$ in the range $10^{2}-2.10^{4} \mathrm{~s}^{-1}$. A possible explanation lies in the increase of the number of particle collisions with the shear rate, promoting disordered aggregation and leading to more aerated final aggregates. The favorable effect of a shear rate increase on the aggregation phenomenon was already reported in the literature in the case of agglomeration of microparticles (David et al., 2003). Although more aerated particles usually means more porous particles, it must be noted that in the present case (particles with small mean pore diameters and narrow pore size distributions), a significant increase of the specific surface area due to more aerated particles is possible even with very small variations of the pore volume $\left(<0.1 \mathrm{~cm}^{3} \cdot \mathrm{g}^{-1}\right)$, for a given mean pore diameter.
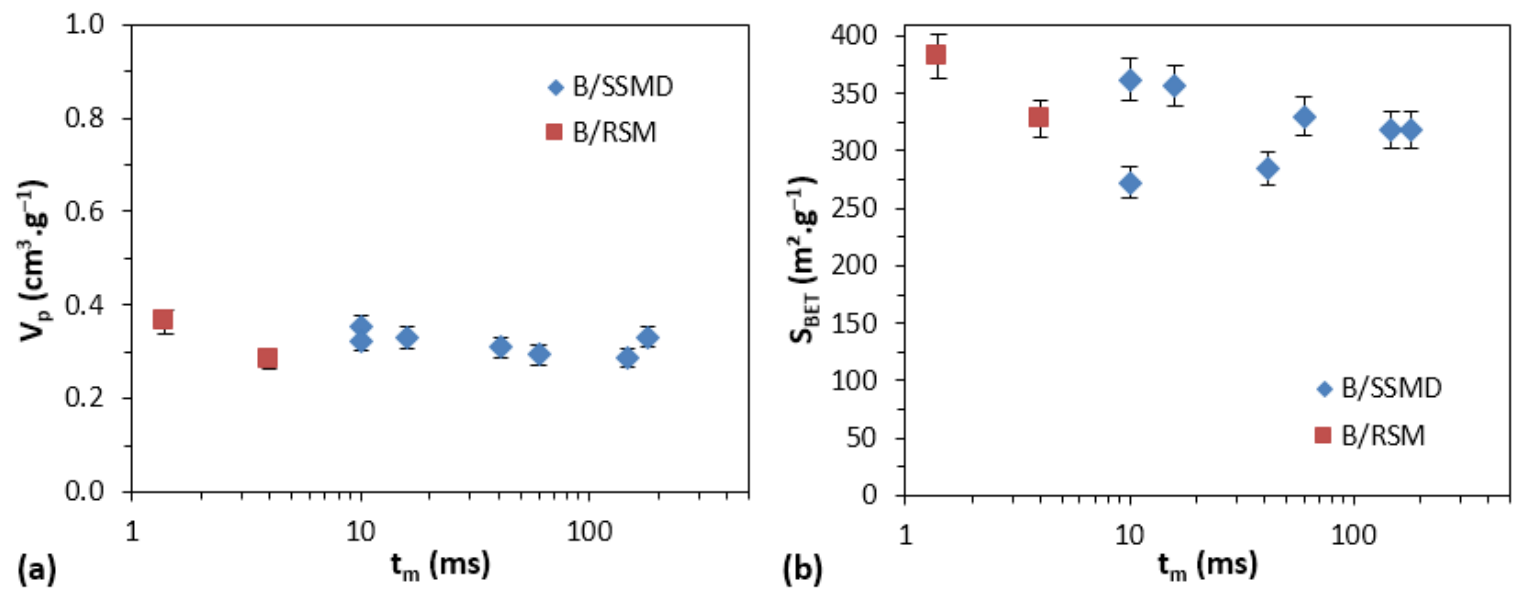

Figure 7. Pore volume (a) and specific surface area (b) evolution with micromixing time of boehmite precipitated in SSMD and RSM. 


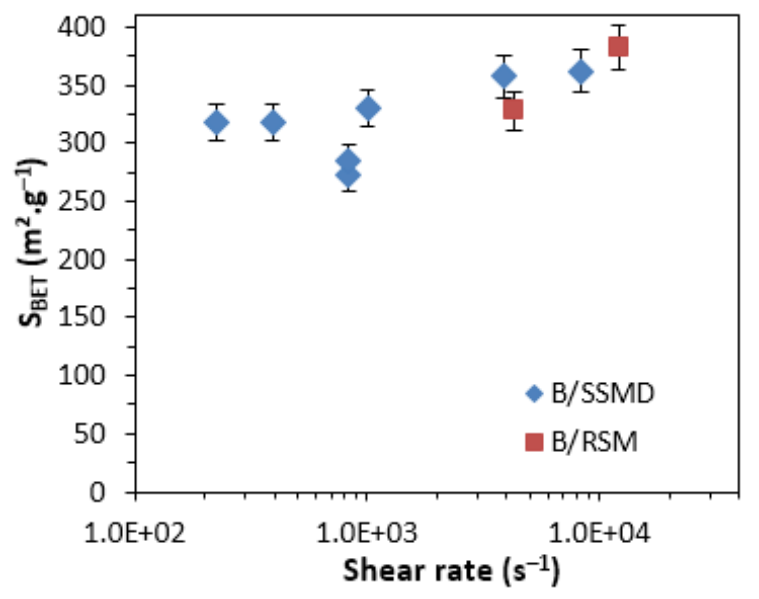

Figure 8. Specific surface area evolution with the shear rate of boehmite precipitated in SSMD and RSM.

Rousseaux et al (1999) have presented some results of the boehmite precipitation with a SSMD in a set of different conditions. Like this study, the influence of the micromixing time on the crystallite size was found to be rather low. The textural properties obtained in such fast mixer were also in the same ranges that the ones measured on boehmite precipitated in stirred reactor. Finally, the use of fast contacting mixers able to promote higher supersaturation levels did not bring any expected benefits: the textural properties of boehmite particles were not enhanced.

\subsection{2 $\mathrm{NH}_{4}$-dawsonite precipitation}

$\mathrm{NH}_{4}$-dawsonite was precipitated in the SSMD and the RSM at different micromixing times (see Table 5). Powder XRD analysis confirmed the presence of a single crystalline phase corresponding to $\mathrm{NH}_{4}$-dawsonite (ICDD 42-0250) and the textural properties were assessed by $\mathrm{N}_{2}$ physisorption (see Table 6). The reproducibility of $\mathrm{NH}_{4}$-dawsonite precipitations in both SSMD and RSM has been investigated by carrying out two or three identical runs for some sets of parameters. Globally, the uncertainties for $\mathrm{NH}_{4}$-dawsonite's crystallite size, specific surface area and pore volume were respectively below $10 \%, 16 \%$ and $11 \%$ at low micromixing times $\left(\mathrm{t}_{\mathrm{m}} \leq 20 \mathrm{~ms}\right)$, and respectively below $9 \%, 10 \%$ and $9 \%$ at high micromixing times $\left(\mathrm{t}_{\mathrm{m}} \geq 60 \mathrm{~ms}\right)$. A better reproducibility was thus obtained for the highest micromixing times of the studied range.

Table 5. Operating parameters investigated for $\mathrm{NH}_{4}$-dawsonite precipitation in the SSMD and the RSM.

\begin{tabular}{|c|c|c|c|c|c|c|c|c|c|c|c|}
\hline Ref. & $\begin{array}{c}\mathrm{C}_{\mathrm{a}} \\
\left(\mathrm{mol} . \mathrm{L}^{-1}\right)\end{array}$ & $\begin{array}{c}\mathrm{C}_{\mathrm{b}} \\
\left(\mathrm{mol} . \mathrm{L}^{-1}\right)\end{array}$ & $\mathrm{R}_{\mathrm{b} / \mathrm{a}}$ & $\begin{array}{c}\mathrm{Q}_{\mathrm{a}} \\
\left(\mathrm{mL} \cdot \mathrm{min}^{-1}\right)\end{array}$ & $\begin{array}{c}\mathrm{Qb}_{\mathrm{b}} \\
\left(\mathrm{mL} \cdot \mathrm{min}^{-1}\right)\end{array}$ & $\begin{array}{c}\mathrm{N} \\
(\mathrm{rpm})\end{array}$ & $\begin{array}{c}\mathrm{r} \\
(\mathrm{mm})\end{array}$ & $\begin{array}{c}\mathrm{h} \\
(\mathrm{mm})\end{array}$ & $\begin{array}{c}\mathrm{C}_{\mathrm{s}} \\
\left(\mathrm{g} \cdot \mathrm{L}^{-1}\right)\end{array}$ & $\begin{array}{l}\mathrm{t}_{\mathrm{m}} \text { (theo) } \\
(\mathrm{ms})\end{array}$ & $\begin{array}{c}\dot{\gamma} \\
\left(\mathrm{s}^{-1}\right)\end{array}$ \\
\hline D/SSMD(01) & 1.20 & 2.00 & 8 & 420.0 & $4 \times 504.0$ & 2000 & 40 & 1.0 & 28.8 & 10 & $8.4 .10^{3}$ \\
\hline D/SSMD(02) & 1.20 & 2.00 & 8 & 84.0 & $4 \times 100.8$ & 2000 & 40 & 1.0 & 28.8 & 10 & $8.4 .10^{3}$ \\
\hline D/SSMD(03) & 1.20 & 2.00 & 8 & 420.0 & $4 \times 504.0$ & 200 & 40 & 1.0 & 28.8 & 10 & $8.4 .10^{2}$ \\
\hline D/SSMD(04) & 1.20 & 2.00 & 8 & 84.0 & $4 \times 100.8$ & 200 & 40 & 1.0 & 28.8 & 19 & $8.4 .10^{2}$ \\
\hline D/SSMD(05) & 1.20 & 2.00 & 8 & 70.0 & $4 \times 84.0$ & 1400 & 40 & 1.5 & 28.8 & 16 & $3.9 .10^{3}$ \\
\hline D/SSMD(06) & 1.20 & 2.00 & 8 & 70.0 & $4 \times 84.0$ & 600 & 40 & 2.5 & 28.8 & 60 & $1.0 .10^{3}$ \\
\hline D/SSMD(07) & 1.20 & 2.00 & 8 & 60.4 & $4 \times 72.5$ & 280 & 40 & 3.0 & 28.8 & 150 & $3.9 .10^{2}$ \\
\hline D/SSMD(08) & 1.20 & 2.00 & 8 & 34.5 & $4 \times 41.4$ & 160 & 40 & 3.0 & 28.8 & 180 & $2.2 .10^{2}$ \\
\hline $\mathrm{D} / \mathrm{RSM}(01)$ & 1.20 & 2.00 & 8 & 172.4 & 827.5 & 7000 & - & - & 28.8 & 1.4 & $1.2 .10^{4}$ \\
\hline $\mathrm{D} / \mathrm{RSM}(02)$ & 1.20 & 2.00 & 8 & 172.4 & 827.5 & 2500 & - & - & 28.8 & 4 & $4.3 \cdot 10^{3}$ \\
\hline
\end{tabular}


Table 6. Properties of $\mathrm{NH}_{4}$-dawsonite precipitated in the SSMD and the RSM.

\begin{tabular}{|c|c|c|c|c|c|}
\hline \multirow{2}{*}{ Ref. } & \multicolumn{2}{|c|}{ Crystallite size } & \multirow{2}{*}{$\begin{array}{c}\mathrm{S}_{\mathrm{BET}} \\
\left(\mathrm{m}^{2} \cdot \mathrm{g}^{-1}\right)\end{array}$} & \multirow{2}{*}{$\begin{array}{c}\mathrm{V}_{\mathrm{p}} \\
\left(\mathrm{cm}^{3} \cdot \mathrm{g}^{-1}\right)\end{array}$} & \multirow{2}{*}{$\begin{array}{c}\mathrm{D}_{\mathrm{p}} \\
(\mathrm{nm})\end{array}$} \\
\hline & $\mathrm{d}_{020}(\mathrm{~nm})$ & $\mathrm{d}_{111}(\mathrm{~nm})$ & & & \\
\hline $\mathrm{D} / \mathrm{SSMD}(01)$ & 4.8 & 7.5 & 184 & 0.36 & 5.6 \\
\hline D/SSMD(02) & 5.4 & 8.1 & 136 & 0.20 & 4.3 \\
\hline D/SSMD(03) & 5.8 & 8.5 & 117 & 0.20 & 4.3 \\
\hline $\mathrm{D} / \mathrm{SSMD}(04)$ & 5.6 & 8.9 & 197 & 0.60 & 5.8 \\
\hline $\mathrm{D} / \mathrm{SSMD}(05)$ & 4.7 & 8.4 & 185 & 0.52 & 6.4 \\
\hline $\mathrm{D} / \mathrm{SSMD}(06)$ & 5.8 & 9.6 & 212 & 0.71 & 6.3 \\
\hline $\mathrm{D} / \mathrm{SSMD}(07)$ & 5.6 & 9.1 & 254 & 0.83 & $6.9-9.1$ \\
\hline D/SSMD(08) & 6.1 & 9.9 & 237 & 0.76 & 9.2 \\
\hline D/RSM(01) & 5.1 & 8.1 & 233 & 0.43 & 5.1 \\
\hline D/RSM(02) & 4.9 & 7.7 & 170 & 0.34 & 5.5 \\
\hline
\end{tabular}

Figure 9 presents the $\mathrm{N}_{2}$ isotherms and pore size distributions of $\mathrm{NH}_{4}$ dawsonite for different micromixing times and type of fast contacting mixers. The type of the mixing device is not decisive. On the contrary, the isotherms and pore size distributions exhibit different profiles, depending on a threshold of micromixing time. For $t_{\mathrm{m}} \leq 10 \mathrm{~ms}$, the isotherm is type IV and the mean pore diameter is centered between 4 and $6 \mathrm{~nm}$. For $\mathrm{t}_{\mathrm{m}} \geq 16 \mathrm{~ms}$, a type II-IV hybrid isotherm was obtained and a large extent of the pore size distribution, as well as a mean pore diameter increase, was noticed. These differences could be related to different morphologies and arrangements of their respective nanoparticles.
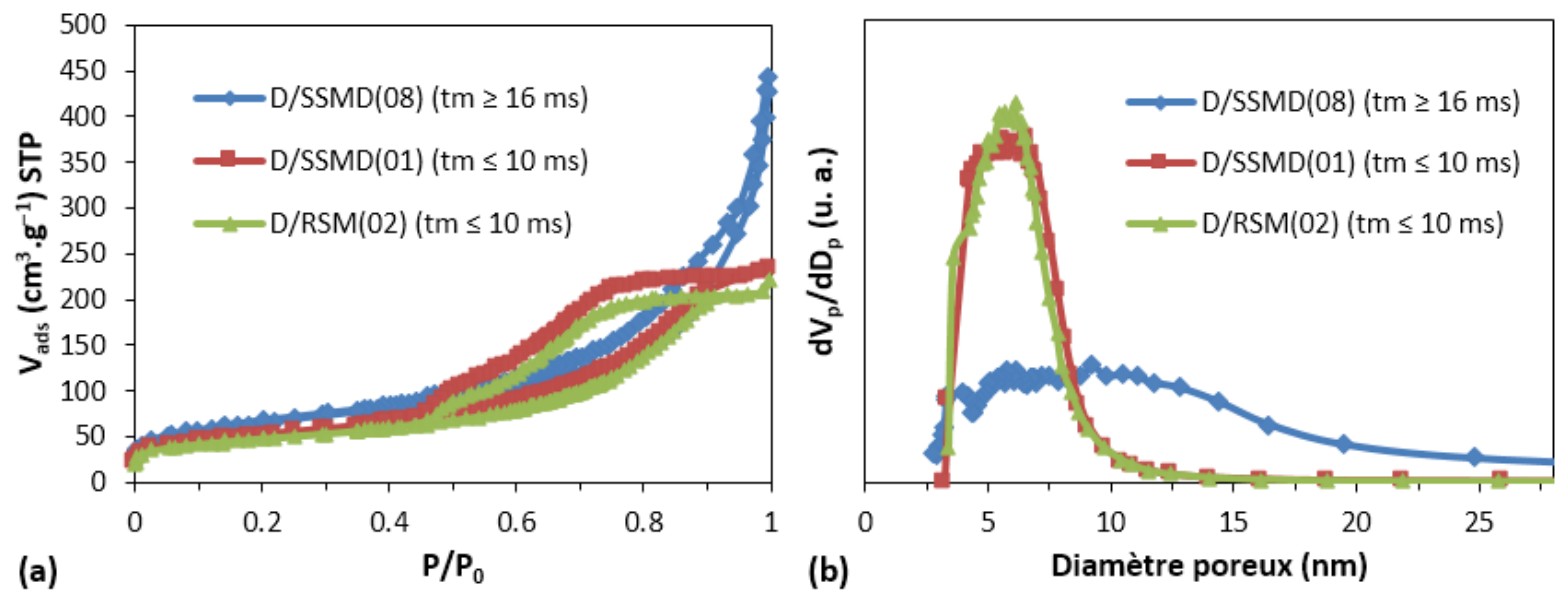

Figure 9. $\mathrm{N}_{2}$ adsorption-desorption isotherms (a) and pore size distributions (b) of $\mathrm{NH}_{4}$-dawsonite obtained by precipitation in fast contacting mixers SSMD and RDT.

Figure 10 presents the evolution of the crystallite mean size with micromixing time for both contacting mixers. Unlike boehmite, $\mathrm{NH}_{4}$-dawsonite appeared to be more sensitive to this operating parameter. Indeed, its average crystallite size, ranging from 7.5 to $8.5 \mathrm{~nm}$ at low micromixing times $\left(\mathrm{t}_{\mathrm{m}} \leq 10 \mathrm{~ms}\right)$, seemed to progressively increase up to $10 \mathrm{~nm}$ with greater micromixing times, although it is difficult to conclude definitely because of the uncertainty on this property. The reduction of the crystallite size with a decrease of the micromixing time would be in accordance with an increase of the supersaturation level in the mixing zone, leading to a more intense primary nucleation. Nevertheless, this evolution seemed to be stopped when the micromixing time was lower than $10 \mathrm{~ms}$. This behavior, partially different from boehmite, 
could not be explained by viscosity of the outlet flow since this one was not pronounced ( 1 to $5 \mathrm{mPa}$.s). A first assumption lies in possible differences between the respective nucleation and growth kinetic rates of $\mathrm{NH}_{4}$-dawsonite and boehmite, which could be the case if considering that $\mathrm{NH}_{4}$-dawsonite is more soluble than boehmite in their respective studied $\mathrm{pH}$ range. It must be noted that this latter hypothesis cannot safely be validated from the current literature, since very few studies have focused on $\mathrm{NH}_{4}$-dawsonite thermodynamic properties and solubility for now; however, according to previous studies, $\mathrm{NH}_{4}$-dawsonite would be more soluble than Na-dawsonite at $25^{\circ} \mathrm{C}$ (Lodziana et al., 2011), which, in turn, would be more soluble than boehmite at $100^{\circ} \mathrm{C}$ and probably below (Bénézeth et al., 2007). A second assumption lies in the colloidal behavior of the $\mathrm{NH}_{4}$-dawsonite particles inside the fast contacting mixer, which is probably different from that of boehmite due to the reactants involved.

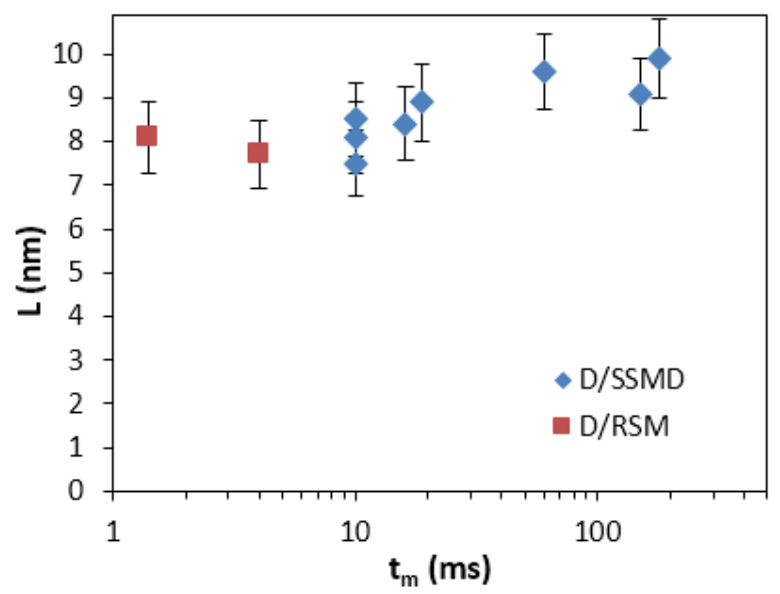

Figure 10. Average crystallite size evolution with micromixing time of $\mathrm{NH}_{4}$-dawsonite precipitated in SSMD and RSM.

Figure 11 presents the influence of the micromixing time on the textural properties of $\mathrm{NH}_{4}$-dawsonite samples precipitated in fast contacting mixers. In the SSMD, the specific surface area and the pore volume both increased with the micromixing time. The evolution, quite limited for the specific surface area, was more pronounced and undoubtable for the pore volume. According to the quality of the mixing conditions, a relatively large range of porosity was thus achievable. A weaker aggregation density of the crystallites may explain this evolution, maybe in combination with the progressive increase of the crystallite size in the pore volume case. In the RSM, however, the previously described trends can hardly be found, particularly for the specific surface area. Thus, the fast contacting mixer's technology could also play a role alongside with the micromixing time itself, but more points are needed in the case of the RSM in order to conclude. The influence of the shear rate in the fast contacting mixers was also investigated: unlike boehmite, this factor did not affect the textural properties of $\mathrm{NH}_{4}$-dawsonite. This confirms that, for $\mathrm{NH}_{4}$-dawsonite in the examined parameters range, controlling the supersaturation in the mixing zone is important, rather than the shear rate.
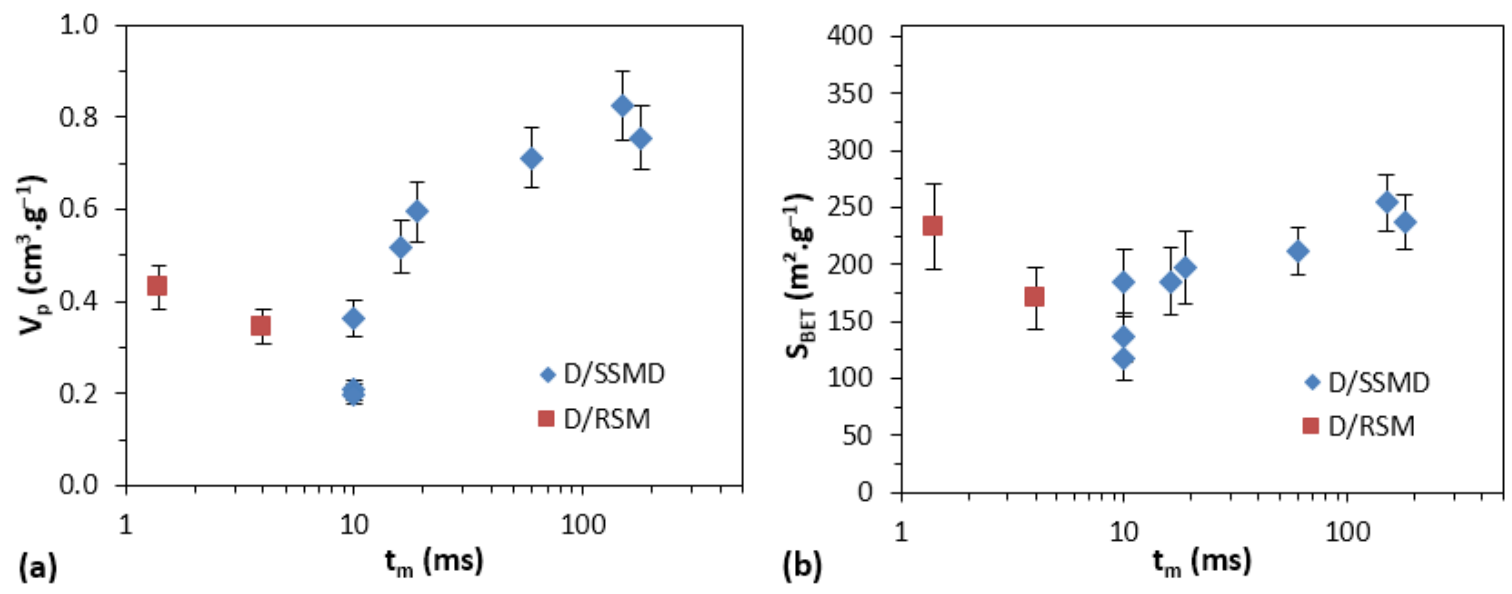

Figure 11. Pore volume (a) and specific surface area (b) evolution with micromixing time of $\mathrm{NH}_{4}$-dawsonite precipitated in SSMD and RSM. 


\section{Conclusion}

This study focused on the precipitation of boehmite, a well-known alumina precursor, and of $\mathrm{NH}_{4}$-dawsonite, an alternative recent alumina precursor, in order to obtain original textural particle properties. Indeed, the properties of alumina-based catalyst supports are to a large extent fixed by the properties of the initial solid precursor. Micromixing conditions were thus investigated, since fast nucleation, growth and aggregation kinetics are involved in such precipitation. Two fast contacting mixers (SSMD and RDT) were designed and operated in continuous mode, in order to control the micromixing conditions in the local zone where the first crystallites appear and to have constant conditions, conversely to the classical batch or semi-batch stirred tank reactor. The micromixing intensity was characterized thanks to the use of a competitive parallel reaction system prior to focusing on the precipitation study. The main findings are summarized as follows:

- Micromixing times ranging from 1 to $4 \mathrm{~ms}$ and from 10 to $200 \mathrm{~ms}$ were achieved with the RDT and the SSMD, respectively. These values assessed from experiments are in correct agreement with the theoretical ones.

- Controlling the micromixing time with fast contacting mixers did not significantly modify the boehmite crystallite size, whatever the operating conditions tested. This result shows that the presence of small numerous crystallites dispersed in the mixing zone may alter the mixing conditions and prevent the occurrence of higher supersaturation levels.

- The boehmite specific surface area evolved with the operating conditions. Its evolution is better understood considering the shear rate level rather than the micromixing times.

- A decrease of the micromixing time led to a reduction of the $\mathrm{NH}_{4}$-dawsonite crystallite size (which could very likely be linked with an increase of the supersaturation level in the mixing zone). This reduction was no more noticed for a micromixing time lower than $10 \mathrm{~ms}$. This behavioral difference between the two precursors may be due to different nucleation and growth kinetics rates, since $\mathrm{NH}_{4}$-dawsonite could possibly be more soluble than boehmite in their respective studied $\mathrm{pH}$ range. Moreover, the reactants involved are largely different, leading to another physicochemical situation in solution.

- It was possible to adjust the $\mathrm{NH}_{4}$-dawsonite pore volume in quite a large extent (from 0.2 to $0.8 \mathrm{~cm}^{3} \cdot \mathrm{g}^{-1}$ ) by controlling the quality of the mixing obtained in the SSMD.

\section{Nomenclature}

$\mathrm{C}_{\mathrm{j}} \quad$ reactants concentration $\left(\mathrm{mol} . \mathrm{L}^{-1}\right)$

$\mathrm{C}_{\mathrm{s}} \quad$ final solid phase concentration (g.L $\mathrm{L}^{-1}$ )

$\mathrm{D}_{\mathrm{p}} \quad$ mean pore diameter $(\mathrm{nm})$

$\mathrm{D}_{\lambda} \quad$ light absorption

e gap between rotor and stator (m)

$\mathrm{h} \quad$ gap between spinning disk and chamber flat bottom (m)

I ionic strength (mol. $\left.\mathrm{L}^{-1}\right)$

$\mathrm{k}_{(\mathrm{j})} \quad \mathrm{n}$-order rate constant of reaction $(\mathrm{j})\left(\mathrm{mol}^{(1-n)} \cdot \mathrm{L}^{(\mathrm{n}-1)} \cdot \mathrm{s}^{-1}\right)$

1 optical path length (m)

L average crystallite size

$\mathrm{n} \quad$ mole number $(\mathrm{mol})$

$\mathrm{N} \quad$ disc rotation speed $\left(\mathrm{s}^{-1}\right)$

$\mathrm{pH}^{*}$ iodine dismutation $\mathrm{pH}$

Q total flowrate $\left(\mathrm{m}^{3} \cdot \mathrm{s}^{-1}\right)$

$\mathrm{Q}_{\mathrm{i}} \quad$ reactants flowrate $\left(\mathrm{m}^{3} \cdot \mathrm{s}^{-1}\right)$

$\mathrm{r} \quad$ lateral feed tubes position $(\mathrm{m})$

$\mathrm{r}_{\mathrm{R}} \quad$ rotor radius $(\mathrm{m})$

$\mathrm{R}_{\mathrm{b} / \mathrm{a}} \quad$ reactants molar ratio

Re Reynold number

$\mathrm{R}_{\mathrm{Q}} \quad$ flowrate ratio of $\mathrm{Q}_{\text {I }}$ over $\mathrm{Q}_{\mathrm{H}}$

$\mathrm{S}_{\mathrm{BET}} \quad$ specific surface area calculated by BET method $\left(\mathrm{m}^{2} \cdot \mathrm{g}^{-1}\right)$

$\mathrm{t}_{\mathrm{m}} \quad$ micromixing time ( $\mathrm{s}$ )

$\mathrm{V}_{\text {ads }}$ adsorbed volume of gas $\left(\mathrm{cm}^{3}\right)$

$\mathrm{V}_{\mathrm{p}}$ pore volume $\left(\mathrm{cm}^{3} \cdot \mathrm{g}^{-1}\right)$

$\mathrm{X}_{\mathrm{S}} \quad$ segregation index

$\mathrm{Y}$ actual yield of the undesired product 
$\mathrm{Y}_{\mathrm{ST}} \quad$ maximum yield of the undesired product

\section{Greek letters}

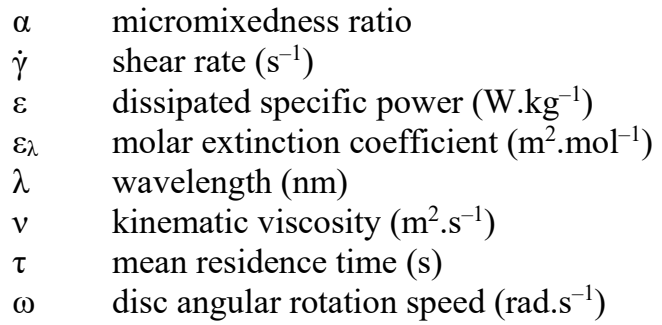

\section{Acknowledgements}

The authors would like to thank the Physics and Analysis Division and the Process Experimentation Division (IFPEN) for technical assistance.

This research did not receive any specific grant from funding agencies in the public, commercial, or not-for-profit sectors.

\section{References}

Ali, A.A., Hasan, M.A., Zaki, M.I., 2005. Dawsonite-Type Precursors for Catalytic Al, Cr, and Fe Oxides: Synthesis and Characterization. Chem. Mater. 17, 6797-6804. doi:10.1021/cm0519131

Aubry, C., Villermaux, J., 1975. Representation du melange imparfait de deux courants de reactifs dans un reacteur agite continu. Chem. Eng. Sci. 30, 457-464. doi:10.1016/0009-2509(75)80015-7

Bałdyga, J., Makowski, Ł., Orciuch, W., 2005. Interaction between mixing, chemical reactions, and precipitation. Ind. Eng. Chem. Res. 44, 5342-5352. doi:10.1021/ie049165x

Bałdyga, J., Pohorecki, R., 1995. Turbulent micromixing in chemical reactors - a review. Chem. Eng. J. 58, 183-195. doi:10.1016/0923-0467(95)02982-6

Barnes, H.A., Hutton, J.F., Walters, K., 1989. An Introduction to Rheology. Elsevier, Amsterdam.

Bénézeth, P., Palmer, D.A., Anovitz, L.M., Horita, J., 2007. Dawsonite synthesis and reevaluation of its thermodynamic properties from solubility measurements: Implications for mineral trapping of $\mathrm{CO} 2$. Geochim. Cosmochim. Acta 71, 4438-4455. doi:10.1016/j.gca.2007.07.003

Bourne, J.R., Studer, M., 1992. Fast reactions in rotor-stator mixers of different size. Chem. Eng. Process. Process Intensif. 31, 285-296. doi:10.1016/0255-2701(92)87002-X

Claassen, J.O., Sandenbergh, R.F., 2007. Influence of mixing on the quality of iron precipitates in zinc-rich solutions. Hydrometallurgy 87, 112-123. doi:10.1016/j.hydromet.2007.02.002

David, R., Espitalier, F., Cameirão, A., Rouleau, L., 2003. Developments in the Understanding and Modeling of the Agglomeration of Suspended Crystals in Crystallization from Solutions. KONA Powder Part. J. 21, 40-53. doi:10.14356/kona.2003008

Duan, X., Kim, T., Li, D., Ma, J., Zheng, W., 2013. Understanding the Effect Models of Ionic Liquids in the Synthesis of $\mathrm{NH} 4$-Dw and $\gamma$-AlOOH Nanostructures and Their Conversion into Porous $\gamma$-Al 2 O 3. Chem. - A Eur. J. 19, 59245937. doi:10.1002/chem. 201203176

Dubert, D.C., Pérez-Ramírez, J., Garcia-Valls, R., 2011. Continuous Synthesis of Porous Ammonium Dawsonite Within a New Microstructrured System. Chem. Eng. Trans. 25, 231-236. doi:10.3303/CET1125039

Euzen, P., Raybaud, P., Krokidis, X., Toulhoat, H., Le Loarer, J.-L., Jolivet, J.-P., Froidefond, C., 2002. Alumina, in: Schüth, F., Sing, K.S.W., Weitkamp, J. (Eds.), Handbook of Porous Solids. Wiley-VCH, Weinheim, pp. 15911677.

Fournier, M.-C., Falk, L., Villermaux, J., 1996a. A new parallel competing reaction system for assessing micromixing efficiency - Determination of micromixing time by a simple mixing model. Chem. Eng. Sci. 51, 5187-5192. doi:10.1016/S0009-2509(96)00340-5

Fournier, M.-C., Falk, L., Villermaux, J., 1996b. A new parallel competing reaction system for assessing micromixing efficiency—Experimental approach. Chem. Eng. Sci. 51, 5053-5064. doi:10.1016/0009-2509(96)00270-9

Franke, J., Mersmann, A., 1995. The influence of the operational conditions on the precipitation process. Chem. Eng. Sci. 50, 1737-1753. doi:10.1016/0009-2509(95)00028-4

Guichardon, P., 1996. Caractérisation chimique du micromélange par la réaction iodure-iodate : application aux milieux visqueux et aux suspensions liquide-solide. Ph.D. thesis, Institut National Polytechnique de Lorraine.

Guichardon, P., Falk, L., 2000. Characterisation of micromixing efficiency by the iodide-iodate reaction system. Part I: experimental procedure. Chem. Eng. Sci. 55, 4233-4243. doi:10.1016/S0009-2509(00)00068-3 
Guichardon, P., Falk, L., Villermaux, J., 2000. Characterisation of micromixing efficiency by the iodide-iodate reaction system. Part II: kinetic study. Chem. Eng. Sci. 55, 4245-4253. doi:10.1016/S0009-2509(00)00069-5

Hu, X., Liu, Y., Tang, Z., Li, G., Zhao, R., Liu, C., 2012. Fabrication of high-surface-area $\gamma$-alumina by thermal decomposition of AACH precursor using low-temperature solid-state reaction. Mater. Res. Bull. 47, 4271-4277. doi:10.1016/j.materresbull.2012.09.019

Kind, M., 2002. Colloidal aspects of precipitation processes. Chem. Eng. Sci. 57, 4287-4293. doi:10.1016/S00092509(02)00345-7

Kowalski, A.J., 2009. An expression for the power consumption of in-line rotor-stator devices. Chem. Eng. Process. Process Intensif. 48, 581-585. doi:10.1016/j.cep.2008.04.002

Lafficher, R., 2016. Nouveau procédé de précipitation pour la synthèse d'alumine. Ph.D. thesis, Université Claude Bernard Lyon 1.

Liu, C., Li, J., Liew, K., Zhu, J., Nordin, M.R. bin, 2012. An environmentally friendly method for the synthesis of nanoalumina with controllable morphologies. RSC Adv. 2, 8352. doi:10.1039/c2ra20674a

Liu, H., Sun, H., Li, J., He, X., Zhu, Z., 2012. pH-dependent formation of AACH fibers with tunable diameters and their in situ transformation to alumina nanocrystals with mesoporous structure. Adv. Powder Technol. 23, $164-169$. doi:10.1016/j.apt.2011.01.008

Łodziana, Z., Stoica, G., Pérez-Ramírez, J., 2011. Reevaluation of the Structure and Fundamental Physical Properties of Dawsonites by DFT Studies. Inorg. Chem. 50, 2590-2598. doi:10.1021/ic102443h

Ma, C.-C., Zhou, X.-X., Xu, X., Zhu, T., 2001. Synthesis and thermal decomposition of ammonium aluminum carbonate hydroxide (AACH). Mater. Chem. Phys. 72, 374-379. doi:10.1016/S0254-0584(01)00313-3

Mersmann, A., 1999. Crystallization and precipitation. Chem. Eng. Process. Process Intensif. 38, $345-353$. doi:10.1016/S0255-2701(99)00025-2

Renouf, S., 2000. Etude d'un procédé d'émulsification : suivi rhéologique in situ dans un rhéo-émulseur et formation de gouttes primaires dans un champ d'écoulement. Ph.D. thesis, Institut National Polytechnique de Lorraine.

Rousseaux, J.-M., Muhr, H., Plasari, E., 2000. Chemical reactors of special geometry for the precipitation of mineral particles. Can. J. Chem. Eng. 78, 650-662. doi:10.1002/cjce.5450780407

Rousseaux, J., Falk, L., Muhr, H., Plasari, E., 1999. Micromixing efficiency of a novel sliding-surface mixing device. AIChE J. 45, 2203-2213. doi:10.1002/aic.690451018

Santiago, M., Yalfani, M.S., Pérez-Ramírez, J., 2006. In-line dispersion-precipitation method for the synthesis of metalsubstituted dawsonites. Genesis of oxide materials with superior properties. J. Mater. Chem. 16, $2886-2889$. doi:10.1039/B607031K

Schwarzer, H.C., Peukert, W., 2004. Combined experimental/numerical study on the precipitation of nanoparticles. AIChE J. 50, 3234-3247. doi:10.1002/aic.10277

Shin, D.-C., Park, S.S., Kim, J.H., Hong, S.S., Park, J.M., Lee, S.H., Kim, D.S., Lee, G.D., 2014. Study on $\alpha$-alumina precursors prepared using different ammonium salt precipitants. J. Ind. Eng. Chem. 20, 1269-1275. doi:10.1016/j.jiec.2013.07.003

Villermaux, J., Falk, L., Fournier, M.C., Detrez, C., 1992. Use of parallel competing reactions to characterise micromixing efficiency. AIChE Symp. Ser. 286, 6-10.

Vogel, R.F., Marcelin, G., Kehl, W.L., 1984. The preparation of controlled pore alumina. Appl. Catal. 12, $237-248$. doi:10.1016/S0166-9834(00)80294-8 